\title{
Cohort comparisons: emotional well-being among adolescents and older adults
}

\author{
This article was published in the following Dove Press journal: \\ Clinical Interventions in Aging \\ 10 May 2014 \\ Number of times this article has been viewed
}

\author{
Yadollah Abolfathi Momtaz' \\ Tengku Aizan Hamid ${ }^{1,2}$ \\ Rahimah Ibrahim ${ }^{1,2}$ \\ 'Institute of Gerontology, \\ ${ }^{2}$ Department of Human Development \\ and Family Studies, Faculty of Human \\ Ecology, Universiti Putra Malaysia, \\ Serdang, Selangor, Malaysia
}

Background: There are several negative stereotypes about older adults that have negatively influenced people's attitude about aging. The present study compared emotional well-being between older adults and adolescents.

Methods: Data for this study came from 1,403 community-dwelling elderly persons and 1,190 secondary school students and were obtained from two national cross-sectional surveys. Emotional well-being was measured using the World Health Organization-Five Well-Being Index. Data analysis was conducted using a multivariate analysis of covariance with SPSS software version 20 (IBM Corporation, Armonk, NY, USA).

Results: Elderly people significantly scored higher levels of emotional well-being (mean, 62.3; standard deviation, 22.55) than younger people (mean, 57.9; standard deviation, $18.46 ; t, 5.32$; $P \leq 0.001)$. The findings from the multivariate analysis of covariance revealed a significant difference between older adults and younger people in emotional well-being $\left[F_{(3,2587)}=120.21\right.$; $\left.P \leq 0.001 ; \eta^{2}=0.122\right]$ after controlling for sex.

Conclusion: Contrary to negative stereotypes about aging, our findings show a higher level of emotional well-being among older adults compared with younger people.

Keywords: aged, ageism, emotional well-being, positive aging

\section{Introduction}

There are some commonly held beliefs that aging is associated with increased dependency, loss of self-control, incapacity, ailment, social isolation, and disengagement from life. ${ }^{1}$ Misconceptions about older people and aging are called "ageism", "gerontophobia", or "the elderly mystique". ${ }^{2}$ According to Butler's definition of ageism, it has been defined as "a process of systematic stereotyping and discrimination against people because they are old, just as racism and sexism accomplish this for color and gender". ${ }^{3}$ The ageism concept, which appears at the individual, institutional, and societal levels, ${ }^{4}$ is a composite of three components, including cognitive (stereotypes), affective (prejudice), and behavioral (discrimination) components. ${ }^{5}$ There are several cultural myths that tend to encourage ageism. The first myth is chronology, which considers people elderly by virtue of their age. The second myth is that of an inflexible personality, which means that as people age, they become more intolerant and conservative. Third is the myth of misery, which suggests that elderly people are unhappy just because they are older. Fourth, there is the myth of rejection and isolation, which holds that elderly people are rejected from society. Fifth is the myth of dependence and unproductiveness, which declares that older adults are not productive members of society because they are not usually engaged in paid employment.
Correspondence: Tengku Aizan Hamid Institute of Gerontology, Universiti

Putra Malaysia, 43400 UPM,

Serdang, Selangor, Malaysia

Tel +60389472750

Fax +60 389472738

Email aizan@upm.edu.my 
Sixth is the myth of physical ill health, which suggests that illness is part of the aging process and that old age is automatically linked to deterioration. Last is the myth of mental deterioration, which suggests that all older people suffer from mental health problems. ${ }^{6}$ Unfortunately, these myths are reinforced by mass media and gerontological studies, wherein elderly people are generally depicted in a negative light. For example, they are portrayed as immobile; lacking in sex drive; having poor eyesight and hearing; being unable to take care of themselves; being slow, confused, bent, and dowdy; napping; and lacking cognitive abilities. ${ }^{7,8}$ In addition to the mass media, several gerontological studies reinforce, rather than challenge, such ageist stereotypes. ${ }^{2}$ For example, the studies focusing on changes in physical and cognitive functioning of elderly people have extremely portrayed old age as a period of losses, loneliness, and declining physical and cognitive functioning. ${ }^{9-11}$

These negative and prevalent impressions toward aging have dramatically influenced health professional decisions and practices, which consequently have resulted in a failure to deal with treatable symptoms. ${ }^{1,12,13}$ For example, findings from a number of studies show that health professionals often prefer younger people to older adults, as they believe that young people are more productive and have a greater potential to live longer and healthier than older adults do. They may also see health-related problems of elderly people as normal signs of aging, rather than considering signs of illness that may be curable. Unfortunately, these misconceptions have contributed to negative psychological, physical, and health outcomes ${ }^{14}$ and, consequently, to premature deaths of older adults. ${ }^{12}$

All these misconceptions state that elderly people have more problems than younger people. Because this negative conception of older adults is becoming prevalent, resulting in the golden years of life becoming years of frustration and resentment, there is an urgent need for research to highlight the possible positive aspects of old age in society. Therefore, it is imperative to do research that may dispel these myths about aging and give a better idea of old age. Considering the abovementioned misconceptions, this article compares emotional well-being as an important psychosocial marker of health and well-being ${ }^{15}$ between older adults and young people. Emotional well-being has been defined as the possession of the flexibility to deal with the inevitable challenges of life conditions $^{16}$ and having a positive feeling state comprising the affective aspect (happiness) and cognitive aspect (life satisfaction).${ }^{17-19}$ It also refers to the quantitative and qualitative experiences of joy, fascination, sadness, anxiety, anger, and affection that make life pleasant or unpleasant. ${ }^{20}$ The present study compares emotional well-being between older adults and adolescents. The alternative hypothesis of the study was that there would be a significant difference in emotional well-being between older adults and adolescents.

\section{Theoretical framework}

The theoretical framework for this study was developed from Carstensen socioemotional selectivity theory (SST) and wisdom theory. The first theory, which was developed by Carstensen, is the SST. The SST comprises three central concepts: selectivity, emotion, and perception of time. ${ }^{21}$ The awareness of lifetime as a fundamental human characteristic plays an essential role in motivation. Goals are often set within temporal contexts, and goal selection depends fundamentally on the perception of time. The SST focuses on two main classes of psychological goals. The first comprises expansive goals, such as acquiring knowledge or making new social networks. In contrast, the second encompasses goals related to feeling states, such as pursuing positive emotional experiences. ${ }^{22}$ According to the SST, people's goal selection is based on their perspectives regarding time. Since most elderly people have already lost their parents and other ascending kin, their awareness of the fact that life is finite increases, and they become more selective about how to spend their remaining lifetime. Instead of trying to spend their time in pursuit of varied experiences, they tend to use their time on activities that enhance their positive emotions and maximize their emotional well-being. ${ }^{21}$

In contrast, when people consciously or unconsciously perceive time as open-ended (in the case of young people), they are likely to be less selective with their time. They seek to gain resources to build their future, even though the experience is stressful and unpleasant. ${ }^{23}$ The SST maintains that perception of time horizons influences the selection of goals. When perceived as open-ended, time is associated with seeking new experiences and achievement-oriented stimuli; for example, gathering new information and experiencing new knowledge. In contrast, when time is perceived as finite, it is linked to a stronger focus on emotionally relevant stimuli and interpersonal connectedness. For example, goals emphasize feeling states, mostly regulation of emotional states to optimize well-being. ${ }^{24}$ According to this theory, aging often involves a decrease in the experience of negative affect and is linked to a stabilization or even a slight increase in the experience of positive affect. ${ }^{25}$ As people get older and their perceived remaining lifetime is decreased, current emotional goals associated with well-being become more important. Because people selectively attend to information that is 
consistent with their current goals, information processing in the elderly might be characterized by a positivity bias. Research shows that older adults are more likely to forget negative and more likely to remember positive information compared with younger adults. ${ }^{26}$ Compared with young people, the elderly were less likely to reserve negative information, but not positive information. ${ }^{25}$ Older adults people have a more positive perspective than younger people. ${ }^{27}$

Another theory that may explain possible generational differences in emotional well-being is wisdom theory. Wisdom as a key factor in the creation of a good life and has been defined as expertise in the conduct and meaning of life that is associated with a high degree of personal and interpersonal competence, such as the ability to listen, evaluate, and give counsel. ${ }^{28}$ Although wisdom has been widely defined, there are some agreements that it involves the use of certain kinds of pragmatic reasoning to navigate important life challenges. ${ }^{29}$ Baltes and Smith also define wisdom as having useful knowledge to deal with life problems, including an awareness of the varied contexts of life, acknowledgement that values and life goals vary among individuals and groups, and recognition of the uncertainties of life, along with ways to deal with them. ${ }^{30}$ This reflects that wisdom influences people's approach to life conflicts. Because growing older may be related to the acquisition of wisdom-related concepts about life development, ${ }^{31-34}$ it is believed that older persons are aware of ontogenetic changes, which may include the positivity effect. Within this theory, a wise person is someone who can understand what is most important in life and knows the way to reach it. The wise person knows the things that make life worthwhile and meaningful. ${ }^{28}$ According to the earlier discussion, it could be speculated that older adults may have higher levels of emotional well-being compared with adolescents.

\section{Methodology}

Data for this study were obtained from two surveys in Malaysia: Mental and Spiritual Well-Being among Adolescents (MSWBA) ${ }^{35}$ and Patterns of Social Relationship and Psychological Well-Being Among Older Persons in Peninsular Malaysia (PSRPWO) ${ }^{36}$ In both of these surveys, emotional well-being was measured using the World Health Organization (WHO)-Five Well-Being Index (WHO-5). ${ }^{35,36}$ The MSWBA was conducted from 2009 to 2010. The survey employed a self-group-administered questionnaire, which was distributed to 1,200 Malay students selected using a multistage proportional stratified random sampling method. The MSWBA was carried out at two stages. In the first stage, a simple random sampling technique was used to select schools from different districts. Finally, the survey questionnaires were administered to all students in the selected schools, resulting in a sample of 1,200 respondents. Of the 1,200 questionnaires distributed, 1,190 were returned. The PSRPWO was carried out from 2007 to 2009. The focus of the study was on a pattern of social relationship and psychological well-being in Peninsular Malaysia. The details of methodology have been published in full elsewhere. ${ }^{35,36}$ Briefly, a multistage cluster sampling design was used to obtain a representative sample of community-dwelling elderly persons living in Peninsular Malaysia. The PSRPWO employed a face-to-face interview technique to collect data in respondents' homes with standardized questionnaires by trained interviewers. A subsample of 1,403 elderly Malay aged 60 years and older was used for the present study.

\section{Measure}

Emotional well-being was measured using the WHO-5, a wellvalidated and widely used measure of positive well-being. The scale covers positive mood (good spirits, relaxation), vitality (being active and waking up fresh and rested), and general interests (being interested in things). ${ }^{37}$ Because the WHO-5 well-being index was originally developed for adults, it is important to assess the readability of the measure. For this purpose, the Flesch Reading Ease (FRE) was used. The FRE rates text on a 100-point scale on the basis of the average number of syllables per word and words per sentence. The higher the FRE score, the better the readability. ${ }^{38}$ The FRE score obtained was 85.58 , indicating that the WHO-5 could be read and understood by those with a ninth-grade reading level.

\section{Results}

The elderly group comprised 1,403 community-dwelling elderly persons aged 60 years or older, with approximately equal sex distribution ( $50.8 \%$ women, $49.2 \%$ men). The young group included 534 male and 656 female secondary school students with a median age of 16 years. Table 1 displays the sociodemographic characteristics of the subjects by age group.

Elderly people scored significantly higher levels of emotional well-being (mean, 62.3; standard deviation, 22.55) than younger participants (mean, 57.9; standard deviation, 18.46; $t=5.32 ; P \leq 0.001$ ). Using the commonly used criterion of a WHO-5 score lower than 52, suggesting poor emotional well-being, ${ }^{39,40} 29.4 \%$ of older adults compared with $34.7 \%$ of young people reported poor emotional well-being $\left(\chi^{2}=8.46\right.$; $P<0.01)$. 
Table I Sociodemographic characteristics of the subjects by age group

\begin{tabular}{|c|c|c|c|c|}
\hline \multirow[t]{2}{*}{ Variable } & \multicolumn{2}{|c|}{ Older adults } & \multicolumn{2}{|c|}{ Adolescents } \\
\hline & $\mathbf{n}$ & $\%$ & $\mathbf{n}$ & $\%$ \\
\hline \multicolumn{5}{|l|}{ Sex } \\
\hline Female & 713 & 50.8 & 656 & 55.1 \\
\hline Male & 690 & 49.2 & 534 & 44.9 \\
\hline \multicolumn{5}{|l|}{ Marital status } \\
\hline Married & 743 & 53.0 & 0 & 0.0 \\
\hline Unmarried & 660 & 47.0 & 1,190 & 100.0 \\
\hline \multicolumn{5}{|l|}{ Education } \\
\hline No formal education & 481 & 34.3 & & \\
\hline Primary education & 780 & 55.6 & & \\
\hline Secondary education & 130 & 9.3 & 1,190 & 100.0 \\
\hline Tertiary education & 12 & 0.9 & & \\
\hline Living arrangements & & 0.0 & & \\
\hline Living with family & $\mathrm{I}, 208$ & 86.1 & $\mathrm{I}, 0 \mathrm{II}$ & 85.0 \\
\hline Living with others & 78 & 5.6 & 179 & 15.0 \\
\hline Living alone & 117 & 8.3 & 0 & 0.0 \\
\hline
\end{tabular}

A multivariate analysis of covariance (MANCOVA) was used to compare the emotional well-being of older adults and young people (positive mood, emotional vitality, and general interests) after controlling for sex. Before conducting the MANCOVA, a series of Pearson correlations were conducted between all of the dependent variables to examine the assumption that the dependent variables would be moderately correlated with each other. ${ }^{41}$ As shown in Table 2, a meaningful pattern of correlations was observed among all of the dependent variables, suggesting the appropriateness of a MANCOVA. In addition, Box's test of equality of covariance was significant (Box's $\mathrm{M}=74.94 ; P<0.001$ ). This means that the assumption of equality of covariance matrices has been violated, which tests the null hypothesis that the covariance matrices between the groups are equal. However, this is not much of a problem with a large sample size. Therefore, because Pillai's criterion is most robust for violations of test assumptions, ${ }^{42}$ it was used in interpreting the MANCOVA results.

As presented in Table 3, the results of MANCOVA revealed a statistically significant difference between older

Table 2 Means, standard deviations, and correlation matrix of the emotional well-being subscales

\begin{tabular}{llllll}
\hline $\begin{array}{l}\text { Dependent } \\
\text { variable }\end{array}$ & $\begin{array}{l}\text { Positive } \\
\text { mood }\end{array}$ & $\begin{array}{l}\text { General } \\
\text { interests }\end{array}$ & Vitality & Mean & $\begin{array}{l}\text { Standard } \\
\text { deviation }\end{array}$ \\
\hline Positive mood & & $0.445^{*}$ & $0.617^{*}$ & 6.58 & 2.36 \\
General & & & $0.535^{*}$ & 2.67 & 1.51 \\
interests & & & & & \\
Vitality & & & & 5.83 & 2.35 \\
\hline
\end{tabular}

Note: $* P \leq 0.001$.
Table 3 The results of multivariate analysis of covariance

\begin{tabular}{lllll}
\hline $\begin{array}{l}\text { Main } \\
\text { effect }\end{array}$ & $\begin{array}{l}\text { Pillai's } \\
\text { trace }\end{array}$ & $\boldsymbol{F}$ & $\begin{array}{l}\text { Degrees } \\
\text { of freedom }\end{array}$ & $\eta^{2}$ \\
\hline Group & 0.122 & $120.21^{*}$ & 3,2587 & 0.122 \\
Sex & 0.020 & $18.06^{*}$ & 3,2587 & 0.020 \\
\hline
\end{tabular}

Notes: $\eta^{2}$, partial eta squared. $* P \leq 0.00$ I.

adults and young people on the combined dependent variables $\left[F_{(3,2587)}=120.21 ; P \leq 0.001 ; \eta^{2}=0.122\right]$. The main effect of sex was also significant $\left[F_{(3,2587)}=18.06 ; P \leq 0.001 ; \eta^{2}=0.02\right]$. However, the multivariate effect size for main effect of sex was small.

Finally, univariate analyses for each dependent variable as follow-up tests to the MANCOVA, using the Bonferroni method for controlling type I error rates, were conducted to examine individual mean difference across two groups and well-being subscales. As shown in Tables 3 and 4, the results revealed a significant mean difference between older adults and young people in positive $\operatorname{mood}\left[F_{(1,251)}=125.63 ; P \leq 0.001\right.$; $\left.\eta^{2}=0.05\right]$, vitality $\left[F_{(1,2591)}=25.09 ; P \leq 0.001 ; \eta^{2}=0.01\right]$, and general interests $\left[F_{(1,2591)}=57.70 ; P \leq 0.001 ; \eta^{2}=0.02\right]$.

Overall, MANCOVA results indicate significant group differences in emotional well-being, wherein elderly people score higher on the emotional well-being scale than young respondents.

\section{Discussion}

The current study was designed to compare emotional wellbeing between older adults and young people. The findings from this study, as hypothesized, revealed that older adults had a higher level of emotional well-being compared with young people. Our findings supported and extended existing research attempting to dispel misconceptions about aging. For example, Lee and Knight, ${ }^{43}$ in their study on a sample of 103 young people (mean age, 19.95 years; standard deviation, 2.12) and 44 older adults (mean age, 71.75; standard deviation, 6.35) found that older persons have significantly lower anxiety scores than the young people. ${ }^{43}$ Likewise, the findings from another study aiming to compare the psychological well-being of elderly people (mean age, 73 years) with that of young people (mean age, 20 years) showed that older adults significantly scored lower than young people on several indices of psychopathology including trait anxiety, neuroticism, schizotypal personality, rumination, and thought suppression. ${ }^{44}$ Our results are also consistent with findings from a recent study conducted on a random large sample size among adult Americans. It is generally believed that elderly people suffer from sleep problems more than younger people, 
Table 4 The means and standard deviations of the emotional well-being subscales for two groups

\begin{tabular}{|c|c|c|c|c|c|c|c|c|}
\hline \multirow[t]{2}{*}{ Variable } & \multicolumn{2}{|c|}{ Elderly } & \multicolumn{2}{|c|}{ Young } & \multirow{2}{*}{$\begin{array}{l}\text { Degrees } \\
\text { of freedom }\end{array}$} & \multirow[t]{2}{*}{$F$} & \multirow[t]{2}{*}{$\eta^{2}$} & \multirow[t]{2}{*}{ Contrast } \\
\hline & Mean & SD & Mean & SD & & & & \\
\hline Positive mood & 7.05 & 2.45 & 6.02 & 2.13 & I, 259I & $125.63 *$ & 0.05 & Elderly $<$ young \\
\hline Vitality & 6.06 & 2.53 & 5.57 & 2.11 & I, 259| & $25.09 *$ & 0.01 & Elderly $<$ young \\
\hline General interests & 2.47 & 1.60 & 2.90 & 1.37 & I, 259| & $57.70^{*}$ & 0.02 & Young $<$ elderly \\
\hline
\end{tabular}

Note: $* P \leq 0.001$.

Abbreviations: $\eta^{2}$, partial eta squared; SD, standard deviation.

but the findings from Grandner et al's study reveal that sleep quality appears to improve over a lifetime. ${ }^{45}$ The results are also consistent with Carstensen et al's study ${ }^{46}$ showing that older adults, compared with young people, have a higher ability to escape bad moods. Similarly, our findings are also consistent with the recent study conducted by Stone et al, ${ }^{47}$ who found that older persons were happier and less stressed than younger people.

These findings can also support the hypothesis that emotional well-being may remain stable and intact in old age, and that despite having social losses, loneliness, declining physical and mental functioning, and cognitive impairments, elderly people have higher emotional well-being. ${ }^{48,49}$

The higher levels of emotional well-being of older adults compared with adolescents can be explained by Carstensen et al' ${ }^{50} \mathrm{SST}$, which maintains that as people age and perceive their time horizons become shorter, they focus on more immediate goals that elicit positive emotions. Young people, in contrast, often need to explore or take risks to achieve longer-range goals, and they experience stress and frustration. ${ }^{50}$ The results also agree with Baltes ${ }^{51}$ theory, in which wisdom and emotional intelligence increase with age. In other words, as people get older, their abilities to understand and develop strategies to avoid or at least lessen the possible emotional conflicts increase.

A further explanation to justify why elderly people compared with younger adults have a higher level of emotional well-being has been provided by Isaacowitz, ${ }^{52}$ who found that elderly people, when compared with young people, prefer positive outlook patterns and show the most positive outlook, which helps them regulate their mood and, consequently, leads to better emotional well-being. ${ }^{52} \mathrm{He}$ also found that in certain situations, young people mostly pay more attention to emotionally negative information, and elderly people are more likely to pay attention to emotionally positive information. Compared with young age, elderly people are more able to process positive stimuli while ignoring spontaneous reactions to negative stimuli. ${ }^{53}$ As people get older, they are more emotionally balanced and better able to solve emotional problems. There is also evidence that older adults are more positive and less negative than younger adults. ${ }^{54}$ There is also more evidence that as people grow older, negativity preference reduces compared with increased positivity preference. In other words, elderly people tend to see the good things in life more easily and are less likely to be affected by negative events. This evidence implies that aging is not characterized by an overoptimistic view of life but, instead, by an increasing ability to be less affected by negative events. ${ }^{55}$ The theory maintains that increased attention to emotional goals leads to greater complexity of emotional experience and, consequently, better regulation of emotions experienced in everyday life. ${ }^{22}$ Another possibility that can explain higher levels of emotional well-being among older adults compared with young people is that they are more religious than young people and attach a high value to religious beliefs that strengthen them to enable effective coping with stress and losses. ${ }^{56,57}$ In Malaysia, where culture and religion overlap, the elderly Malays view the process of aging as God's will and believe that this world is temporary and there is a life after death, which enables them to view stressful experiences as less threatening and to cope more effectively with age-related changes and losses. Therefore, their religious beliefs and practice positively influence their emotional well-being. ${ }^{58,59}$

Although the results of this study show that elderly people had higher levels of emotional well-being compared with adolescents, it is worth mentioning that the pattern of greater well-being in old age may represent the well-being paradox, which refers to the notion that older adults report high psychological well-being despite increased age-related changes and life challenges ${ }^{60}$ The review of the literature focusing on the well-being in old age reveals several reasons that many older adults paradoxically report high levels of well-being and life satisfaction. First, the high pattern of well-being in old age may not generalize to all dimensions of well-being. Second, this pattern of the association between well-being and age may exist only in rich countries. Third, age: wellbeing associations may vary across sex and ethnicity. Another 
reason that older adults may, paradoxically, report higher levels of well-being is as a result of the inevitable influence of survivorship and the fact that people with lower well-being die earlier. ${ }^{61,62}$

\section{Conclusion}

Contrary to negative ageist stereotypes of miserable elderly, the findings from the present study showed that elderly people compared with young people have better emotional well-being. The findings support SST. With regard to the well-known powerful influence of mass media on people's opinions, it is suggested that the findings from the present study be employed by the media to demonstrate more positive images of older people, which may promote positive attitudes toward aging. As a last word, it is noteworthy that although negative perceptions of older people are not totally without foundation, ${ }^{63}$ the problems of the elderly are greatly exaggerated. In other words, it can be argued that increasing problems with age are a nonlinear phenomenon that may be mediated and moderated by factors other than physiologic aging.

The most important limitation of the present study that should be highlighted is its cross-sectional design, which makes it difficult to make a precise conclusion regarding emotional well-being trends over time. Therefore, a further study using a longitudinal approach is needed to assess changes of emotional well-being across the life span.

\section{Acknowledgement}

This article is based on two studies funded by Universiti Putra Malaysia through the Research Universiti Grant Scheme (RUGS-91827) and the Ministry of Science, Technology and Innovation under ScienceFund Grant (04-01-04-SF0479).

\section{Disclosure}

The authors report no conflicts of interest in this work.

\section{References}

1. Gridley H, Wells Y, Browning C, et al. Psychology and ageing: Contributions to the International Year of Older Persons. Paper presented at: 34th annual meeting of the Australian Psychological Society; September 1999; Hobart.

2. Palmore E. Advantages of aging. Gerontologist. 1979;19(2):220-224.

3. Butler RN. Why Survive? Being Old in America. New York: Harper \& Row; 1975.

4. Butler RN. Combating ageism. Int Psychogeriatr. 2009;21(2):211.

5. Iversen TN, Larsen L, Solem PE. A conceptual analysis of ageism. Nordic Psychology. 2009;61(3):4-22.

6. McInnes A. Meldrew or Methuselah: The mythology of old age. Generations Rev. 2004;14(4):22-24.

7. Vasil L, Wass H. Portrayal of the elderly in the media: literature review and implications for educational gerontologists. Educational Gerontology. 1993;19:71-85.
8. Cuddy AJC, Fiske ST. Doddering but dear: process, content, and function in stereotyping of older persons. In: Nelson T, editor. Ageism: Stereotyping and Prejudice Against Older Persons. Boston: MIT Press; 2002:3-26.

9. Momtaz YA, Hamid TA, Ibrahim R. Unmet needs among disabled elderly Malaysians. Soc Sci Med. 2012;75(5):859-863.

10. Momtaz YA, Hamid TA, Yusoff S, et al. Loneliness as a risk factor for hypertension in later life. J Aging Health. 2012;24(4):696-710.

11. Momtaz YA, Hamid TA, Nurizan Y, Ibrahim R. Widowhood and psychological well-being among older Malayslans: Mediating effect of social network. Indian J Social Work. 2009;70(3):375-390.

12. Nolan LC. Dimensions of aging and belonging for the older person and the effects of ageism. BYU J Public Law. 2011;25(2):317-339.

13. Rosowsky E. Ageism and professional training in aging: Who will be there to help? Generations. 2005;29(3):55-58.

14. Rashid A, Ong EK, Wong ESY. The attitude towards ageing among residents of an elderly care institution in Penang Malaysia. Int J Collaborative Res Intern Med Public Health. 2012;4(6): 1069-1083.

15. Brown HE, Gilson ND, Burton NW, Brown WJ. Does physical activity impact on presenteeism and other indicators of workplace well-being? Sports Med. 2011;41(3):249-262.

16. Tom-Orme L. Traditional beliefs and attitudes about diabetes among Navajos and Utes. In: Joe JR, Young RS, eitords. Diabetes as a Disease of Civilization: Impact of Culture in Indigenous People. New York: Mouton de Gruyter; 1994:271-291.

17. Hillman K, McMillan J. Life Satisfaction of Young Australians: Relationships between Further Education, Training and Employment and General and Career Satisfaction. Melbourne: Australian Council for Educational Research; 2005. Available from: http://research.acer. edu.au/cgi/viewcontent.cgi?article=1046\&context=lsay_research. Accessed March 31, 2014.

18. Cicognani E, Albanesi C, Zani B. The impact of residential context on adolescents' subjective well being. Jo Community Appl Social Psychol. 2008;18(6):558-575.

19. Lee GR, Ishii-Kuntz M. Social interaction, loneliness, and emotional well-being among the elderly. Res Aging. 1987;9(4):459-482.

20. Kahneman D, Deaton A. High income improves evaluation of life but not emotional well-being. Proc Natl Acad Sci U S A. 2010;107(38): 16489-16493.

21. Carstensen LL, Isaacowitz DM, Charles ST. Taking time seriously. A theory of socioemotional selectivity. Am Psychol. 1999;54(3): 165-181.

22. Carstensen LL, Fung HH, Charles ST. Socioemotional selectivity theory and the regulation of emotion in the second half of life. Motivation Emotion. 2003;27(2):103-123.

23. Kalat JW, Shiota MN. Emotion. Belmont, CA: Wadsworth Publishing; 2007.

24. Carstensen LL. The influence of a sense of time on human development. Science. 2006;312(5782):1913-1915.

25. Goeleven E, De Raedt R, Dierckx E. The positivity effect in older adults: the role of affective interference and inhibition. Aging Ment Health. 2010;14(2):129-137.

26. Charles ST, Mather M, Carstensen LL. Aging and emotional memory: the forgettable nature of negative images for older adults. J Exp Psychol Gen. 2003;132(2):310-324.

27. Sullivan SJ, Mikels JA, Carstensen LL. You never lose the ages you've been: affective perspective taking in older adults. Psychol Aging. 2010;25(1):229-234.

28. Baltes PB, Staudinger UM. Wisdom. A metaheuristic (pragmatic) to orchestrate mind and virtue toward excellence. Am Psychol. 2000;55(1): 122-136.

29. Grossmann I, Karasawa M, Izumi S, et al. Aging and wisdom: culture matters. Psychol Sci. 2012; 23(10):1059-1066.

30. Baltes PB, Smith J. The fascination of wisdom: its nature, ontogeny, and function. Perspectives Psychol Sci. 2008;3(1):56-64. 
31. Jeste DV, Ardelt M, Blazer D, Kraemer HC, Vaillant G, Meeks TW. Expert consensus on characteristics of wisdom: a Delphi method study. Gerontologist. 2010;50(5):668-680.

32. Baltes PB, Staudinger UM, Maercker A, Smith J. People nominated as wise: a comparative study of wisdom-related knowledge. Psychol Aging. 1995;10(2):155-166.

33. Glück J, Baltes PB. Using the concept of wisdom to enhance the expression of wisdom knowledge: not the philosopher's dream but differential effects of developmental preparedness. Psychol Aging. 2006;21(4): 679-690.

34. Woodward K. Against wisdom: The social politics of anger and aging. Cultural Critique. 2002;51:186-218.

35. Yahaya N, Momtaz YA, Othman M, Sulaiman N, Mat F. Spiritual wellbeing and mental health among Malaysian adolescents. Life Science Journal. 2012;9(1):440-448.

36. Abolfathi Momtaz Y, Hamid TA, Ibrahim R, Yahaya N, Abdullah SS Moderating effect of Islamic religiosity on the relationship between chronic medical conditions and psychological well-being among elderly Malays. Psychogeriatrics. 2012;12(1):43-53.

37. Bech P. Measuring the dimension of psychological general well-being by the WHO-5. Quality of Life Newsl. 2004;32:15-16.

38. Stacks DW. Primer of Public Relations Research. New York: Guilford; 2002.

39. Pouwer F, Geelhoed-Duijvestijn PH, Tack CJ, et al. Prevalence of comorbid depression is high in out-patients with Type 1 or Type 2 diabetes mellitus. Results from three out-patient clinics in The Netherlands. Diabet Med. 2010; 27(2):217-224.

40. Roy T, Lloyd CE, Parvin M, Mohiuddin KG, Rahman M. Prevalence of co-morbid depression in out-patients with type 2 diabetes mellitus in Bangladesh. BMC Psychiatry. 2012;12:123.

41. Meyers LS, Gamst G, Guarino AJ. Applied Multivariate Research: Design and Interpretation. Thousand Oaks, CA: Sage Publishers; 2006.

42. Johnson CR, Field CA. Using fixed-effects model multivariate analysis of variance in marine biology and ecology. Oceanogr Marine Biol Annu Rev. 1993;31:177-221.

43. Lee LO, Knight BG. Attentional bias for threat in older adults: moderation of the positivity bias by trait anxiety and stimulus modality. Psychol Aging. 2009;24(3):741-747.

44. Erskine JA, Kvavilashvili L, Conway MA, Myers L. The effects of age on psychopathology, well-being and repressive coping. Aging Ment Health. 2007;11(4):394-404.

45. Grandner MA, Martin JL, Patel NP, et al. Age and sleep disturbances among American men and women: data from the US Behavioral Risk Factor Surveillance System. Sleep. 2012;35(3):395-406.

46. Carstensen LL, Pasupathi M, Mayr U, Nesselroade JR. Emotional experience in everyday life across the adult life span. J Pers Soc Psychol. 2000;79(4):644-655.
47. Stone AA, Schwartz JE, Broderick JE, Deaton A. A snapshot of the age distribution of psychological well-being in the United States. Proc Natl Acad Sci U S A. 2010;107(22):9985-9990.

48. Hahn J, Oishi S. Psychological needs and emotional well-being in older and younger Koreans and Americans. Personality Individual Differences. 2006;40(4):689-698.

49. Smith J, Fleeson W, Geiselmann B, Settersten R, Kunzmann U. Sources of well-being in old age. In: Baltes PB, Mayer KU, editors. The Berlin Aging Study: Aging from 70 to 100. Cambridge: Cambridge University Press; 1999:450-471.

50. Carstensen LL, Turan B, Scheibe S, et al. Emotional experience improves with age: evidence based on over 10 years of experience sampling. Psychol Aging. 2011;26(1):21-33.

51. Baltes PB. Extending longevity: Dignity gain - or dignity drain? Max Planck Res. 2003;3:14-19.

52. Isaacowitz DM. Mood Regulation in Real-Time: Age Differences in the Role of Looking. Curr Dir Psychol Sci. 2012;21(4):237-242.

53. Feng MC, Courtney CG, Mather M, Dawson ME, Davison GC. Agerelated affective modulation of the startle eyeblink response: older adults startle most when viewing positive pictures. Psychol Aging. 2011;26(3): $752-760$.

54. von Hippel W, Henry JD, Matovic D. Aging and social satisfaction: offsetting positive and negative effects. Psychol Aging. 2008;23(2): $435-439$.

55. Isaacowitz DM, Toner K, Goren D, Wilson HR. Looking while unhappy: mood-congruent gaze in young adults, positive gaze in older adults. Psychol Sci. 2008;19(9):848-853.

56. Mehrotra CM, Wagner LS. Aging and Diversity: An Active Learning Experience. Washington, DC: Taylor and Francis; 1998.

57. Berk LE. Development through the Lifespan. 5th ed. Boston, MA Pearson, Allyn and Bacon; 2010.

58. Momtaz YA, Ibrahim R, Hamid TA, Yahaya N. Mediating effects of social and personal religiosity on the psychological well being of widowed elderly people. Omega (Westport). 2010;61(2):145-162.

59. Momtaz YA, Hamid TA, Ibrahim R, Yahaya N, Chai ST. Moderating effect of religiosity on the relationship between social isolation and psychological well-being. Mental Health Religion Culture. 2012;14(2): $141-156$.

60. Wiesmann U, Hannich HJ. A salutogenic analysis of the well-being paradox in older age. J Happiness Stud. 2013. 2014;15(2):339-355.

61. Hansen T, Slagsvold B. The age and subjective well-being paradox revisited: a multidimensional perspective. Norsk Epidemiol. 2012;22(2): $187-195$.

62. Kunzmann U, Little TD, Smith J. Is age-related stability of subjective well-being a paradox? Cross-sectional and longitudinal evidence from the Berlin Aging Study. Psychol Aging. 2000;15(3):511-526.

63. Arnold J. Managing Careers into the 21st Century. London: Paul Chapman; 1997.
Clinical Interventions in Aging

\section{Publish your work in this journal}

Clinical Interventions in Aging is an international, peer-reviewed journal focusing on evidence-based reports on the value or lack thereof of treatments intended to prevent or delay the onset of maladaptive correlates of aging in human beings. This journal is indexed on PubMed Central, MedLine, the American Chemical Society's 'Chemical Abstracts Ser-

\section{Dovepress}

vice' (CAS), Scopus and the Elsevier Bibliographic databases. The manuscript management system is completely online and includes a very quick and fair peer-review system, which is all easy to use. Visit http://www.dovepress.com/testimonials.php to read real quotes from published authors. 